\title{
Sagittal abdominal diameter and its socioeconomic correlates: perspective of sex differences
}

\author{
Chang Li ${ }^{1}$, Marcelline Harris ${ }^{1}$, Dennis Tsilimingras², Sophia Z. Liư ${ }^{3}$, Ying Sheng ${ }^{4}$ and Xuefeng Liu ${ }^{1,5^{*}}$ (D)
}

\begin{abstract}
Background: Sagittal abdominal diameter (SAD) is an anthropometric index associated with visceral adiposity. It remains unclear whether SAD and its socio-economic correlates differ in women and men, which limits the epidemiological and clinical applications of the SAD measurement. The aims of this study are to examine the sex differences in SAD and its socio-economic correlates.
\end{abstract}

Methods: A complex stratified multistage clustered sampling design was used to select 6975 men and 7079 women aged 18 years or more from the National Health Nutrition and Examination Survey 2011-2016, representative of the US civilian non-institutionalized population. SAD was measured in accordance to the standard protocols using a two-arm abdominal caliper. The sex differences in SAD and its socio-economic correlates were evaluated by performing weighted independent $t$ tests and weighted multiple regression.

Results: SAD was lower in women than in men in the entire sample, as well as in all the subgroups characterized by age, race, birth place, household income, and body mass index except for non-Hispanic blacks and those with household income $<\$ 20,000$. Adjusted for other characteristics, age, birth place, household income, and body mass index were associated with SAD in both women and men. Black women were associated with higher SAD then white women $(p<.0001)$, and Hispanic and Asian men were associated with lower SAD than white men (both $p<.01$ ). Women born in other countries were more likely to have lower SAD than women born in the US $(p<.0001)$, and so were men $(p=.0118)$. Both women and men with a household income of $<\$ 75,000$ had higher SAD than those with an income of over $\$ 75,000$. The associations of age, race, and household income with SAD differed in women and men.

Conclusion: SAD is lower in women than in men, in the general population as well as in the most socioeconomic subgroups. While socio-economic correlates of SAD are similar in women and men, the associations of age, race, and household income with SAD vary across sex.

Keywords: Sagittal abdominal diameter, Visceral adiposity, Sex, Waist circumference, Abdominal obesity

\footnotetext{
* Correspondence: liuxf@umich.edu

'Department of Systems, Population, and Leadership, University of Michigan

School of Nursing, Ann Arbor, Ml 48109, USA

${ }^{5}$ Frankel Cardiovascular Center, University of Michigan School of Medicine,

Ann Arbor, Ml 48109, USA

Full list of author information is available at the end of the article
}

(C) The Author(s). 2021 Open Access This article is licensed under a Creative Commons Attribution 4.0 International License, which permits use, sharing, adaptation, distribution and reproduction in any medium or format, as long as you give appropriate credit to the original author(s) and the source, provide a link to the Creative Commons licence, and indicate if changes were made. The images or other third party material in this article are included in the article's Creative Commons licence, unless indicated otherwise in a credit line to the material. If material is not included in the article's Creative Commons licence and your intended use is not permitted by statutory regulation or exceeds the permitted use, you will need to obtain permission directly from the copyright holder. To view a copy of this licence, visit http://creativecommons.org/licenses/by/4.0/ The Creative Commons Public Domain Dedication waiver (http://creativecommons.org/publicdomain/zero/1.0/) applies to the data made available in this article, unless otherwise stated in a credit line to the data. 


\section{Background}

Accumulating evidence suggests that visceral adipose tissue is more strongly related to metabolic risk factors than subcutaneous adipose tissue [1, 2]. Waist circumference (WC) does not distinguish visceral from subcutaneous adipose tissue, and hence cannot accurately reflect levels of visceral adipose tissue [3]. Instead, sagittal abdominal diameter (SAD) is a simple inexpensive anthropometric measure of visceral adiposity [3], and in some studies, has been shown more useful than other anthropometric measurements, including $\mathrm{WC}$ and body mass index (BMI), in assessing health risk $[4,5]$. SAD has beeen linked to increased risks of cardiometabolic disorders [5-7] and mortality $[8,9]$.

Women are reported to have lower intra-abdominal/ visceral adiposity than men while the difference is diminished and not consistently seen in the elderly [1012]. It remains relatively unknown whether SAD, as a manifest measure of visceral adiposity, differs by sex in the general population and in the subgroups defined by socio-economic characteristics. A few studies have evaluated anthropometric measures (including SAD) by sex $[13,14]$; yet small sample size, lack of SAD focus, and lack of assessment of SAD in socio-economic subgroups limit the evaluations of sex difference in SAD. Identification of the sex difference in SAD is crucial for better understanding heath disparities in cardiometabolic outcomes among men and women and improving health care for both sexes.

Socio-economic factors, such as age, sex, and education have been linked to the population distribution of SAD in a descriptive population study in Finland [15]. Another recent study has associated certain socio-economic factors with $\mathrm{SAD} /$ height ratio in the US representative population [13]. To date, sex differences in the associations of socio-economic factors with SAD have not been fully investigated. Knowledge of sex-specific socio-economic factors associated with SAD could promote the development of sex specific interventions to prevent obesity-related health disparities.

In this study, we used anthropometric data from the US National Health and Nutrition Examination Survey (NHANES) to address: 1) Sex differences in SAD in the entire population as well as in the subgroups characterized by age, race/ethnicity, education, birth place, and household income; 2) Sex differences in socio-economic correlates of SAD. Considering the important role of sex in cardiovascular diseases [16] and the important role of SAD in obesity-related health risks [5-9], our findings will provide useful insights for investigating cardiometabolic risk separately in men and women.

\section{Methods}

\section{Data source and study population}

Beginning in 1999, continuous NHANES is conducted by the National Center for Health Statistics in the Centers for Disease Control and Prevention. It includes a series of two-year cross-sectional nationally representative survey of US civilian noninstitutionalized population $[17,18]$. Each survey consists of interview and examination. For each individual, an interview is completed in his/her home, and a health examination is conduted in a mobile examination center. The interview collects demographic, socioeconomic, dietary, and other questionnaire-related data. The examination collects medical, dental, and physiological, and laboratory data. Using a multistage stratified complex probability sampling design, NHANES oversamples older adults, low-income individuals, and certain racial/ethnic groups; participants were assigned weights to account for their unequal sampling probability and nonresponse. All the participants gave informed consent, and the survey was approved by the National Center for Health Statistics Institutional/Ethics Review Board.

In the present study, the sample of participants were chosen from the three most recent cycles of NHANES conducted in 2011-2016. The choice of cycles was determined by data availability of SAD, the only outcome measure in the present study: 2011-2012 represents the first cycle of collecting SAD measurements, and 20152016 is the most recent cycle for which data are available. Participants aged less than 18 years who were interviewed only but not examined, who were pregnant during the examination, and/or who had SAD measurements missed, were excluded from the study based on the following considerations. SAD, similar to BMI and WC, may have different definitions or meanings between children and adults, and the purpose of this study was to examine sex differences in SAD among adults. Participants with 'interview only' missed the examination of SAD which was our focus measure in the study. Pregnant women experienced dramatic changes in physiology and body shape, and their normal levels of SAD could not be reflected. After applying the above exclusion criteria, we had 14,054 individuals in the final study sample, including 6975 men and 7079 women.

\section{Sagittal abdominal diameter}

SAD was measured by a trained examiner when the participant was in the supine position on an examination table (Figure 1) [19]. An abdominal caliper of proper size with lower and upper arms (Holtain Model 609XL, Seritex Inc., NJ, USA) were used to establish the external distance between the front of the abdomen and the small of the back at the iliac level line. The participant 

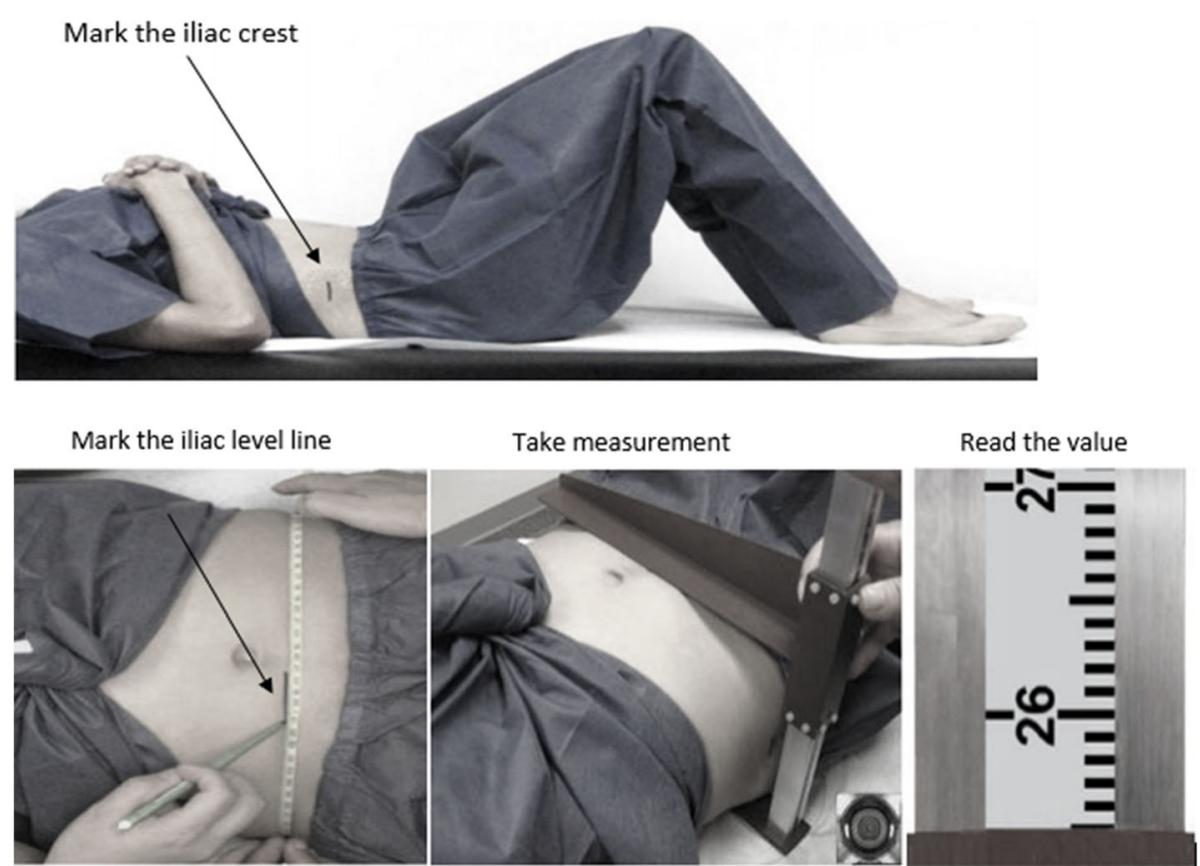

Fig. 1 Measurement of sagittal abdominal diameter $(\mathrm{cm})$ by use of a sliding-beam caliper (The images are taken from the National Health and Nutrition Examination Survey: Anthropometry Procedures Manual, 2016 [19])

was first asked to lie down on the table, bend his or her knees at a 90 degree angle with feet resting flat on the table and arms crossed over the chest. The right and left iliac crests were located, and a line perpendicular to the table on the uppermost lateral border of the right ilium was drawn. A measuring tape was extended over the abdomen without compressing the skin from the left iliac crest to the mark on the right iliac crest. A horizontal line was drawn around $5 \mathrm{~cm}$ long, on the abdomen along the iliac level line on the top left edge of the tape.

The caliper's lower arm was inserted under the small of the back making sure the upper arm exceeds the participant's abdominal diameter. The shaft of the caliper was adjusted in a vertical position. The caliper's upper arm was slid down to lightly touch the abdomen with the edge aligned with the iliac level line mark after the participant took in a gentle breath, slowly let the air out and then paused. The measurement was taken when the participant was in the resting phase and the caliper's shaft was in the vertical position. Up to four SAD readings were taken following the above procedure. The SAD for each person was calculated as an average over the readings.

\section{Socio-economic characteristics}

Socio-economic characteristics considered in this study were all self-reported, including age, sex, race, education, birth place, and household income. They were chosen from a large number of socio-economic variables using model selection techniques and were only significant variables in relation to SAD. Age was categorized as under $30,30-39,40-49,50-59$, and 60 years or more. Race/ethnicity included non-Hispanic white, nonHispanic black, non-Hispanic Asian, Hispanic, and other. The level of education was categorized as high school below, high school graduate/GED or equivalent, and college or above in terms of years in school. Birth place had two categories: born in the US and born in other countries. The family income was grouped into 4 categories: less than $\$ 20,000, \$ 20,000-\$ 44,999, \$ 45$, $000-\$ 74,999$, and $\$ 75,000$ or more. Weight and height were measured using standardized techniques and equipment. BMI was calculated as weight in kilograms divided by the square of height in meters, and then categorized as normal weight (BMI less than $25.0 \mathrm{~kg} / \mathrm{m}^{2}$ ), overweight (BMI greater than 25.0 and less than $29.9 \mathrm{~kg} / \mathrm{m}^{2}$ ), and obesity (BMI greater than or equal to $30.0 \mathrm{~kg} / \mathrm{m}^{2}$ ).

\section{Statistical analysis}

The NHANES supporting and analytical guidelines for surveys 2011-2016 were followed [20]. Stratum, cluster and weight design techniques for survey data were incorporated into data analysis to ensure the representativeness and generalization of the estimates. All the data analyses were performed on PC with 
windows 10 using survey procedures in SAS version 9.4 (SAS Institute Inc., Cary, NC).

Percentages and standard errors were calculated for categorical variables for men and women to examine sex difference in socio-economic characteristics of subjects. The significance of difference in percentages was tested using weighted $x^{2}$ tests. To assess unadjusted sex difference in SAD, means and standard errors of SAD were calculated for men and women in each group define by the categories of age, race, education, birth place, household income, and BMI. Weighted independent $t$ tests were used to compare the means of SAD between men and women.

Weighted multiple regression was performed with SAD as a dependent variable and socio-economic characteristics as independent variables including age, sex, race/ethnicity, education, birth place, household income, and BMI. Regression coefficients and standard errors with 95\% confidence intervals (CIs) were estimated and adjusted associations of sex with SAD were examined. Wald $\chi^{2}$ tests were useed to examine the significance of parameter estimates. The model was then conducted separately in women and men to identify socio-economic correlates of SAD and the sex differences in associations of the correlates with SAD were test by using weighted independent $t$ tests.

\section{Results}

\section{Socio-economic characteristics}

Average age of the study participants was 47.3 years: 47.4 years for women and 47.2 years for men. From Table 1, we can see that women were $50.4 \%$ and men 49.6\%. Hispanics were 23.9\%, non-Hispanic Asian 12.0\%, non-Hispanic blacks $22.3 \%$, and non-Hispanic whites $38.6 \%$. Compared to men, women were more likely to be Hispanic, have a college education or above, live in a poorer household, and be obese.

\section{Sex difference in SAD}

Overall, SAD was lower in women than in men $(22.2$ vs. 23.1, $p<.0001$ ) (Table 2). Analysis of sex difference in SAD by characteristics shows that compared to men, women had lower SAD for all subgroups defined by age, race/ethnicity, education, birth place, household income, and BMI except for non-Hispanic blacks and those with household income less than $\$ 20,000$ in which men and women have comparable SAD. In addition, Table 2 also shows that non-Hispanic blacks had the highest SAD and non-Hispanic Asians had the lowest SAD among racial/ethnic groups. Adults with household income greater than $\$ 75,000$ had the lowest SAD and those with income less than $\$ 20,000$ had the highest SAD among income groups.

\section{Trend in SAD over time and age}

SAD was consistently lower in women than in men over the survey period (Figure 2) and age (Figure 3). There were no increasing trends in SAD over the survey period (trend $p=.23$ ), but there were increasing trends over age (trend $p<.0001$ ) for both women and men. In both women and men, SAD increased more rapidly at the age of 50 years or below compared to those at the age of $>$ 50 years (Figure 3). The difference in SAD between women and men did not change over age.

\section{Socio-economic correlates of SAD in women and men}

Adjusted for other socioeconomic characteristics, age, sex, race/ethnicity, birth place, household income, and BMI were all associated with SAD (Table 3). Overall, women were $1.3 \mathrm{~cm}$ lower than men in average SAD at any given levels of BMI and other variables $(p<.0001)$. Hispanics and non-Hispanic Asians had lower SAD than non-Hispanic whites whose SAD was lower than nonHispanic blacks. Participants born in other countries had lower SAD than those born in the US. Participants with a household income of over $\$ 75,000$ had lower SAD than those in other income categories of less than $\$ 75$, 000 .

Stratification analysis by sex shows that adjusted for other characteristics, age, birth place, household income, and body mass index were associated with SAD in both women and men (Table 3). Older age groups were associated with higher SAD compared to the group of age 18-29 in both women and men, and the sex differences in age-related associations with SAD are all significant. While both women and men born in other countries had lower SAD than the peers born in the US, the difference in the association of birth place with SAD is not significant between men and women. Income below $\$ 2000$, between $\$ 2000$ and 45,000 , and/or between $\$ 45$, 000 and $\$ 75,000$ were associated with higher SAD than peers with income over $\$ 75,000$ in both women and men, and the sex differences in the associations with SAD were significant $(p=.0021, p<.00001$, and $p=.002$, respectively). Compared to non-Hispanic white, NonHispanic black was associated with higher SAD in women, and Hispanic and non-Hispanic Asian were associated with lower SAD in men. The associations of Hispanic and non-Hispanic black (vs. non-Hispanic white) with SAD differed across sex $(p=.0101$ and $p<.0001$, respectively).

\section{Discussion}

Our results show that SAD was lower in women than in men in the overall population, as well as in the majority of subgroups defined by age, race/ethnicity, birth place, BMI, and household income. For example, in each BMI category (normal weight, overweight, and obesity), 
Table 1 Socio-economic characteristics of participants by sex in NHANES 2011-2016

\begin{tabular}{|c|c|c|c|c|}
\hline \multirow[t]{2}{*}{ Characteristics } & \multirow{2}{*}{$\begin{array}{l}\text { Overall } \\
\text { (\%) }\end{array}$} & \multicolumn{3}{|l|}{ Sex } \\
\hline & & Women (\%) & Men (\%) & $p$-value \\
\hline Age (years) & & & & .0034 \\
\hline Less than 30 & $20.6(.34)$ & $19.7(.47)$ & $21.5(.49)$ & \\
\hline $30-39$ & $17.0(.32)$ & $16.8(.44)$ & $17.1(.45)$ & \\
\hline $40-49$ & $16.8(.32)$ & $17.8(.45)$ & $15.8(.44)$ & \\
\hline $50-59$ & $16.1(.31)$ & $16.6(.44)$ & $15.7(.44)$ & \\
\hline 60 or more & $29.5(.38)$ & $29.2(.54)$ & $29.8(.55)$ & \\
\hline Race/Ethnicity & & & & .015 \\
\hline Hispanic & $23.9(.36)$ & $24.8(.51)$ & $23.0(.50)$ & \\
\hline Non-Hispanic Asian & $12.0(.42)$ & $12.0(.39)$ & $12.1(.39)$ & \\
\hline Non-Hispanic Black & $22.3(.35)$ & $22.5(.50)$ & $22.0(.50)$ & \\
\hline Non-Hispanic White & $38.6(.41)$ & $37.8(.58)$ & $39.4(.59)$ & \\
\hline Other & $3.2(.15)$ & $2.9(.20)$ & $3.5(.22)$ & \\
\hline Education & & & & $<.0001$ \\
\hline Less than 12 th grade & $22.0(.35)$ & $20.7(.48)$ & $23.4(.51)$ & \\
\hline High school graduate/GED or equivalent & $22.3(.35)$ & $20.9(.48)$ & $23.7(.51)$ & \\
\hline College graduate or above & $55.7(.42)$ & $58.5(.59)$ & $52.9(.60)$ & \\
\hline Birth place & & & & .63 \\
\hline in US & $70.8(.38)$ & $70.6(.54)$ & $71.0(.54)$ & \\
\hline in other countries & $29.2(.38)$ & $29.4(.54)$ & $29.0(.54)$ & \\
\hline Household income (dollars) & & & & .0001 \\
\hline Less than $\$ 20,000$ & $21.9(.35)$ & $23.0(.50)$ & $20.7(.49)$ & \\
\hline$\$ 20,000$ to $\$ 44,999$ & $29.8(.39)$ & $30.3(.55)$ & $29.3(.55)$ & \\
\hline$\$ 45,000$ to $\$ 74,999$ & $19.5(.33)$ & $19.4(.47)$ & $19.7(.48)$ & \\
\hline$\$ 75,000$ or more & $28.8(.38)$ & $27.3(.53)$ & $30.3(.55)$ & \\
\hline Body mass index $\left(\mathrm{kg} / \mathrm{m}^{2}\right)$ & & & & $<.0001$ \\
\hline Less than 25 & $31.2(.39)$ & $32.0(.55)$ & $30.3(.55)$ & \\
\hline 25 to 29 & $31.7(.39)$ & $27.0(.53)$ & $36.5(.58)$ & \\
\hline 30 or more & $37.1(.41)$ & $41.0(.58)$ & $33.3(.56)$ & \\
\hline
\end{tabular}

Note: The numbers in the parentheses are estimated standard errors

women tended to have an approximate $1.3 \mathrm{~cm}$ lower mean SAD than men, and the sex difference in SAD did not change over BMI categories (Table 2). In addition, women had a $0.7 \mathrm{~cm}, 1.3 \mathrm{~cm}, 1.1 \mathrm{~cm}, 0.6 \mathrm{~cm}$, and $1.2 \mathrm{~cm}$ lower mean SAD than men in the groups aged $<30,30$ to $<40,40$ to $<50,50$ to $<60$, and $\geq 60$ years, respectively. SAD is a manifest measure of visceral adipose tissues. The sex difference in SAD may be attributed to the observation that women have more abdominal subcutaneous adipose tissue but less visceral adipose tissue compared to men [21, 22].

BMI, WC and SAD are three measures of obesity and are highly correlated (Supplemental Table 1). While BMI is typically used to measure the general obesity, WC is a measure of abdominal obesity, and measures both subcutaneous and visceral adipose tissues [3]. By examining results from diverse studies of WC after matching the age ranges [23-26], we found that WC was lower in women than in men and the change patterns in WC was similar to the patterns in SAD in this study for women and men. WC is widely used to define abdominal obesity with differential reference ranges/cut points for women and men $(88 \mathrm{~cm}$ for women and 102 $\mathrm{cm}$ for men). Similar differential patterns in SAD across sex groups from our study provide evidence for consideration of sex-specific cut points of SAD when assessing the obesity-related health risk by use of SAD.

Although women have a lower mean WC than men, data from two prospective cohort studies of the Health Professionals Follow-up Study and the Nurses' Health Study showed that WC predicted the adjusted relative risk of coronary heart disease in both women and men, 
Table 2 Average sagittal abdominal diameter (cm) by sex among participants in NHANES 2011-2016

\begin{tabular}{|c|c|c|c|c|}
\hline \multirow[t]{2}{*}{ Characteristics } & \multirow[t]{2}{*}{ Overall } & \multicolumn{3}{|l|}{ Sex } \\
\hline & & Women & Men & $p$-value \\
\hline Overall & - & $22.2(.05)$ & $23.1(.05)$ & $<.0001$ \\
\hline \multicolumn{5}{|l|}{ Age (years) } \\
\hline Less than 30 & $20.6(.08)$ & $20.2(.12)$ & $20.9(.11)$ & $<.0001$ \\
\hline $30-39$ & $22.3(.09)$ & $21.6(.13)$ & $22.9(.13)$ & $<.0001$ \\
\hline $40-49$ & $22.9(.09)$ & $22.4(.13)$ & $23.5(.13)$ & $<.0001$ \\
\hline $50-59$ & $23.6(.09)$ & $23.3(.14)$ & $23.9(.13)$ & 0.0011 \\
\hline 60 or more & $23.7(.06)$ & $23.1(.09)$ & $24.3(.09)$ & $<.0001$ \\
\hline \multicolumn{5}{|l|}{ Race/Ethnicity } \\
\hline Hispanic & $22.9(.07)$ & $22.5(.10)$ & $23.4(.10)$ & $<.0001$ \\
\hline Non-Hispanic Asian & $19.6(.08)$ & $18.8(.11)$ & $20.5(.10)$ & $<.0001$ \\
\hline Non-Hispanic Black & $23.7(.08)$ & $23.8(.11)$ & $23.6(.12)$ & .23 \\
\hline Non-Hispanic White & $22.8(.06)$ & $22.1(.09)$ & $23.6(.09)$ & $<.0001$ \\
\hline Other & $22.8(.23)$ & $22.3(.35)$ & $23.2(.31)$ & .05 \\
\hline \multicolumn{5}{|l|}{ Education } \\
\hline Less than 12 th grade & $22.9(.08)$ & $22.7(.11)$ & $23.0(.11)$ & 0.028 \\
\hline High school graduate/GED or equivalent & $23.0(.08)$ & $22.7(.12)$ & $23.3(.11)$ & .0002 \\
\hline College graduate or above & $22.4(.05)$ & $21.8(.07)$ & $23.1(.07)$ & $<.0001$ \\
\hline \multicolumn{5}{|l|}{ Birth place } \\
\hline in US & $23.2(.05)$ & $22.7(.07)$ & $23.6(.07)$ & $<.0001$ \\
\hline in other countries & $21.4(.06)$ & $20.9(.09)$ & $22.0(.08)$ & $<.0001$ \\
\hline \multicolumn{5}{|l|}{ Household income (dollars) } \\
\hline Less than $\$ 20,000$ & $23.1(.08)$ & $23.1(.11)$ & $23.1(.12)$ & .92 \\
\hline$\$ 20,000$ to $\$ 44,999$ & $23.1(.07)$ & $22.8(.10)$ & $23.3(.10)$ & .001 \\
\hline$\$ 45,000$ to $\$ 74,999$ & $22.6(.09)$ & $22.0(.12)$ & $23.3(.12)$ & $<.0001$ \\
\hline$\$ 75,000$ or more & $21.9(.07)$ & $20.9(.10)$ & $22.9(.09)$ & $<.0001$ \\
\hline \multicolumn{5}{|l|}{ Body mass index $\left(\mathrm{kg} / \mathrm{m}^{2}\right)$} \\
\hline Less than 25 & $18.2(.03)$ & $17.6(.04)$ & $18.9(.04)$ & $<.0001$ \\
\hline 25 to 29 & $22.0(.03)$ & $21.3(.05)$ & $22.6(.04)$ & $<.0001$ \\
\hline 30 or more & $26.9(.05)$ & $26.4(.06)$ & $27.7(.07)$ & $<.0001$ \\
\hline
\end{tabular}

Note: The numbers in the parentheses are estimated standard errors

and the correlation between $\mathrm{WC}$ and heart disease was even stronger in women than in men [27]. A different study followed up half a million men and women aged 40-69 years in the United Kingdom and showed that women with bigger waists and waist-to-hip ratios faced a greater excess risk of heart attack than men who had a similar 'apple shape' [28]. SAD was thought to have stronger associations with cardio-metabolic disorders than WC $[5,29]$. In our study, women tended to have a lower SAD than men, similarly to WC, in the overall population, as well as the subgroups determined by age, race, education, etc. However, it remains unclear whether there is a sex difference in the associations of SAD with cardio-metabolic risk, and further study is needed to examine if the association is stronger in women than in men as WC showed in the previous reports. The strong health risk associations of SAD and WC would indicate that more intensive screening for the risk of cardiovascular disease might help prevent the onset of disease in individuals with an apple shape, especially in women.

SAD increased with age, and the trends in men and women were similar with respect to age. The results can be partly explained by the reports on visceral fat change over age in the previous studies [22,30]. The process of aging was associated with substantial fat redistribution among depots [31]. Redistribution of fat from subcutaneous to visceral depots was observed from late middle age until the ninth decade of life. Our results also show that the mean SAD increase was faster among younger 


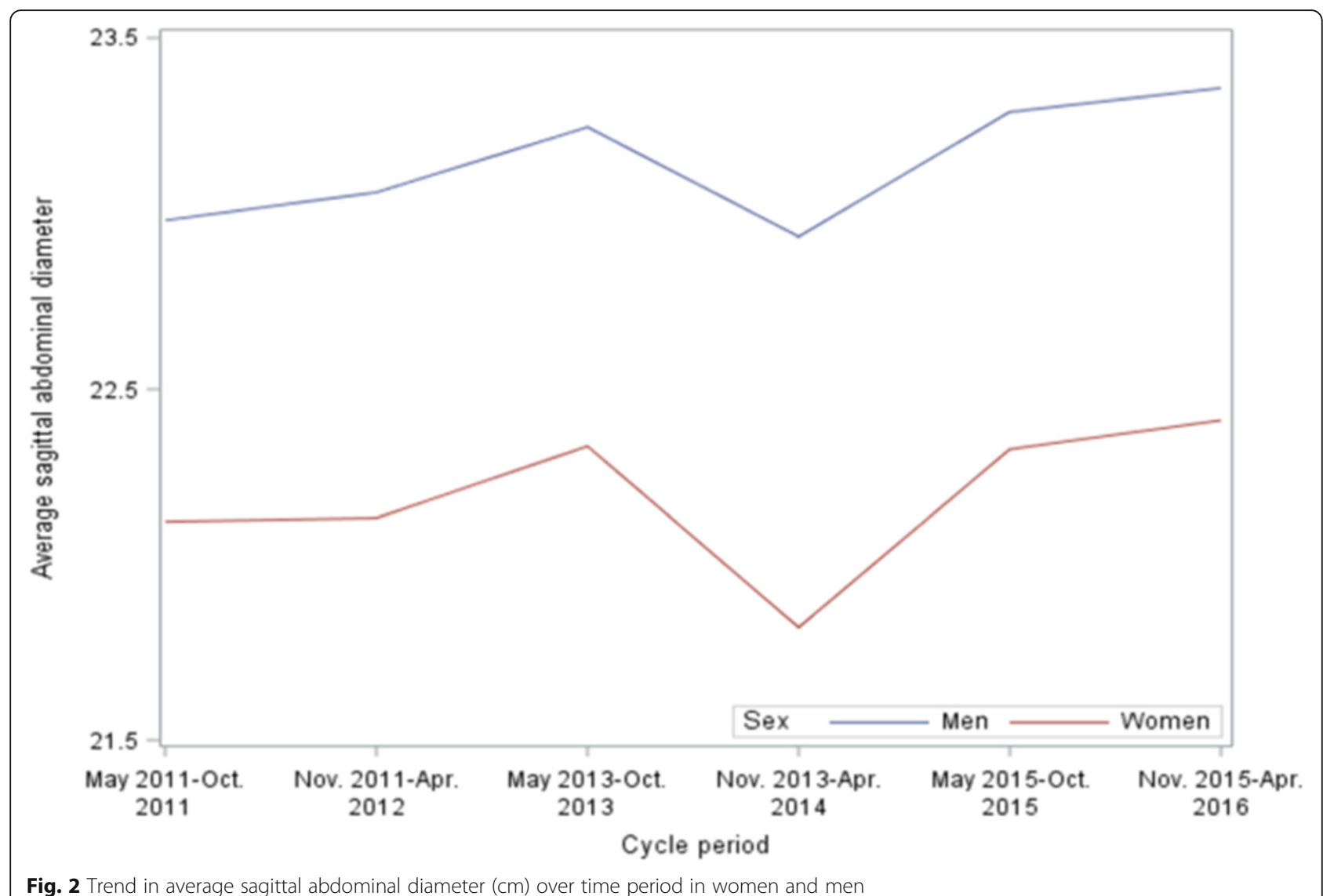

Fig. 2 Trend in average sagittal abdominal diameter (cm) over time period in women and men

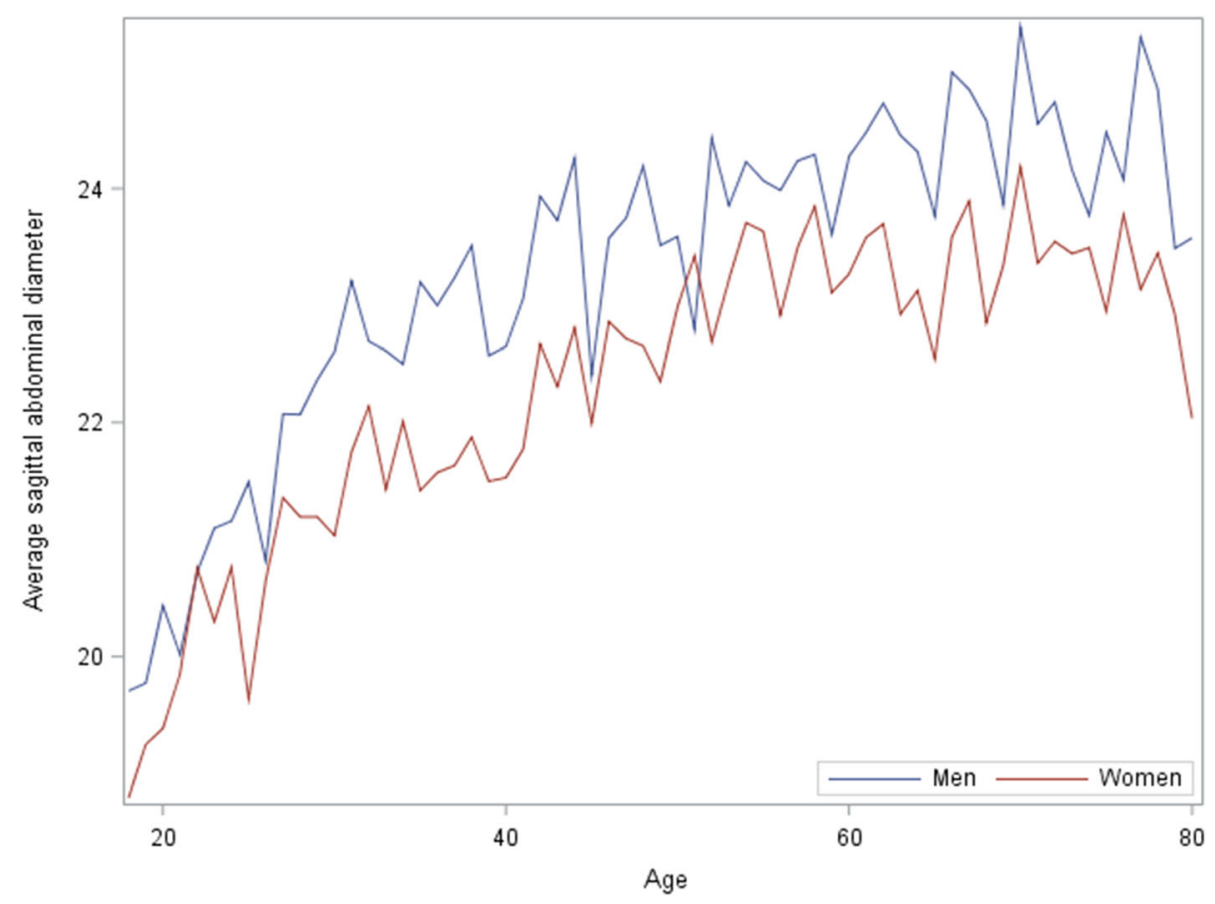

Fig. 3 Change of average sagittal abdominal diameter $(\mathrm{cm})$ with age in women and men 
Table 3 Association of socio-economic factors with sagittal abdominal diameter $(\mathrm{cm})$ in women and men

\begin{tabular}{|c|c|c|c|c|c|c|c|c|c|c|}
\hline \multirow[t]{2}{*}{ Characteristics } & \multicolumn{3}{|l|}{ Overall } & \multicolumn{3}{|l|}{ Women } & \multicolumn{3}{|l|}{ Men } & \multirow{2}{*}{$\begin{array}{l}p \text {-value } \\
\text { for sex } \\
\text { difference }\end{array}$} \\
\hline & Estimate & $95 \% \mathrm{CL}$ & $p$-value & Estimate & $95 \% \mathrm{CL}$ & $p$-value & Estimate & $95 \% \mathrm{CL}$ & $p$-value & \\
\hline \multicolumn{11}{|l|}{ Age (years, vs. < 30) } \\
\hline $30-39$ & $0.8(.07)$ & $0.7,0.9$ & $<.0001$ & $0.7(.10)$ & $0.5,0.9$ & $<.0001$ & $1.0(.09)$ & $0.8,1.2$ & $<.0001$ & .0028 \\
\hline $40-49$ & $1.3(.07)$ & $1.1,1.4$ & $<.0001$ & $1.1(.10)$ & $0.9,1.3$ & $<.0001$ & $1.4(.10)$ & $1.2,1.6$ & $<.0001$ & .0018 \\
\hline $50-59$ & $1.8(.07)$ & $1.6,1.9$ & $<.0001$ & $1.6(.10)$ & $1.4,1.8$ & $<.0001$ & $1.9(.10)$ & $1.7,2.1$ & $<.0001$ & .0106 \\
\hline 60 or more & $2.1(.06)$ & $1.9,2.2$ & $<.0001$ & $1.8(.09)$ & $1.6,1.9$ & $<.0001$ & $2.3(.08)$ & $2.2,2.5$ & $<.0001$ & $<.0001$ \\
\hline \multicolumn{11}{|l|}{ Sex } \\
\hline Women & $-1.3(.04)$ & $-1.4,-1.2$ & $<.0001$ & - & - & - & - & - & - & \\
\hline \multicolumn{11}{|c|}{ Race/Ethnicity (vs. Non-Hispanic white) } \\
\hline Hispanic & $-0.2(.07)$ & $-0.3,-0.1$ & .0037 & $-0.0(.09)$ & $-0.2,0.1$ & .66 & $-0.3(.09)$ & $-0.5,-0.2$ & .0003 & .0101 \\
\hline Non-Hispanic Asian & $-0.2(.09)$ & $-0.4,-0.1$ & .006 & $-0.1(.13)$ & $-0.4,0.1$ & .26 & $-0.3(.12)$ & $-0.6,-0.1$ & .0063 & .60 \\
\hline Non-Hispanic black & $0.3(.06)$ & $0.2,0.4$ & $<.0001$ & $0.5(.08)$ & $0.4,0.7$ & $<.0001$ & $0.0(.08)$ & $-0.1,0.2$ & .63 & $<.0001$ \\
\hline Other Race & $0.1(.12)$ & $-0.1,0.3$ & .30 & $0.3(.18)$ & $-0.1,0.7$ & .11 & $-0.0(.16)$ & $-0.3,0.3$ & .99 & .14 \\
\hline \multicolumn{11}{|l|}{ Education (vs. College or above) } \\
\hline Less than 12 th grade & $-0.0(.06)$ & $-0.2,0.1$ & .54 & $0.0(.09)$ & $-0.1,0.2$ & .71 & $-0.1(.08)$ & $-0.2,0.1$ & .40 & .025 \\
\hline High school or equivalent & $0.0(.05)$ & $-0.1,0.1$ & .76 & $0.1(.08)$ & $-0.1,0.2$ & .26 & $-0.0(.07)$ & $-0.2,0.1$ & .61 & .0224 \\
\hline \multicolumn{11}{|l|}{ Birth place (vs. in the US) } \\
\hline In other countries & $-0.6(.06)$ & $-0.7,-0.5$ & $<.0001$ & $-0.7(.09)$ & $-0.9,-0.5$ & $<.0001$ & $-0.5(.09)$ & $-0.7,-0.4$ & $<.0001$ & .35 \\
\hline \multicolumn{11}{|c|}{ Household income (vs. $\$ 75,000$ or above) } \\
\hline Under $\$ 20,000$ & $0.5(.06)$ & $0.4,0.7$ & $<.0001$ & $0.8(.09)$ & $0.6,1.0$ & $<.0001$ & $0.3(.09)$ & $0.1,0.5$ & .0006 & .0021 \\
\hline$\$ 20,000-\$ 44,999$ & $0.5(.06)$ & $0.4,0.6$ & $<.0001$ & $0.6(.08)$ & $0.5,0.8$ & $<.0001$ & $0.4(.08)$ & $0.2,0.5$ & $<.0001$ & $<.0001$ \\
\hline$\$ 45,000-\$ 74,999$ & $0.3(.06)$ & $0.1,0.4$ & $<.0001$ & $0.2(.09)$ & $0.1,0.4$ & .0071 & $0.3(.09)$ & $0.1,0.5$ & .0009 & .002 \\
\hline \multicolumn{11}{|c|}{ Body mass index $\left(\mathrm{kg} / \mathrm{m}^{2}\right.$, vs. <25) } \\
\hline 25 to 29 & $3.3(.05)$ & $3.2,3.4$ & $<.0001$ & $3.3(.08)$ & $3.1,3.4$ & $<.0001$ & $3.3(.07)$ & $3.2,3.5$ & $<.0001$ & .38 \\
\hline 30 or more & $8.3(.05)$ & $8.2,8.4$ & $<.0001$ & $8.2(.07)$ & $8.0,8.3$ & $<.0001$ & $8.4(.08)$ & $8.2,8.6$ & $<.0001$ & .07 \\
\hline
\end{tabular}

Note: The numbers in the parentheses are estimated standard errors

adults aged $<50$ years compared to older ones aged $>50$ years for both women and men (Figure 3). The change in SAD over age in our study is similar to WC [22], implying that body fat (both subcutaneous and visceral fat) is mostly accumulated in the first half of the life even though it continues until an older age. Both SAD [5-7] and WC [32] have been associated with cardiometabolic risk which is the leading cause of death in the US and worldwide. The prevention of excess fat in the early life could play a critical role in preventing or delaying obesity-related cardiovascular risk for both women and men.

Although mean BMI and WC among women and men increase in trends for the last two decades, the trends have leveled off in recent years after 2010 [33]. In this study, increasing trends in SAD were not significant for both women and men in 2011-2016, indicating no overall SAD increase over time. This is consistent with trends in BMI and WC, implying that the increases in anthropometric measures of obesity reach a plateau.
Numerous obesity prevention and education programs may play an important role in reducing the increasing trend.

In this study, socio-economic correlates of SAD were similar in women and men. Older age, higher BMI, born in the US, and lower household income were all associated with higher SAD in both women and men. However, race/ethnicity groups were differently associated with SAD. Compared to non-Hispanic whites, being Hispanic and non-Hispanic Asian was associated with lower SAD in men but not in women; being non-Hispanic black was associated with higher SAD in women but not in men. A study of subjects, including 66 African American, 72 Hispanic, and 47 white men and women, showed that middle-aged and older African-American men and women had lower visceral fat than Hispanic and white peers. The reports are controversial to our results about racial/ethnic difference in SAD that measures levels of visceral fat. We conducted an analysis using a nationally representative sample of 14,054 individuals, including 
3134 non-Hispanic blacks, 3359 Hispanics, and 5425 non-Hispanic whites, and therefore, our data had more power to reflect the difference in visceral fat among racial/ethnic groups.

NHNAES is a national survey of the US civilian noninstitutionalized population using a complex stratified multi-stage sampling design. By incorporating into data analysis the features of NHANES design including sampling weights, selection probabilities, and geographic clustering, our results can reasonably be generalized to the entire US non-institutionalized population and the socioeconomic subpopulations of men and women. Another strength of our study is the large sample size that ensures the analysis power for robust and unbiased estimates when comparing the difference in SAD between women and men across socio-economic subgroups. There are several limitations in this study. NHANES is a cross-sectional survey, and the associations of socio-economic factors with SAD could not be interpreted as causal effects. SAD was measured by a two-arm sliding-beam caliper with the possibility of certain levels of measurement errors in SAD. However, trained examiners recorded 4 repeated SAD readings that could minimize the measurement errors. Certain other factors not considered in this study could confound the results, as we focused on sex difference in SAD and its correlates.

\section{Conclusions}

In summary, women had lower SAD than men not only in the overall population, but in the majority of subgroups determined by socio-economic factors, such as age, race, birth place and household income. Given that increased sagittal diameter is linked to intra-abdominal fatness and cardiometabolic risk in both men and women [5, 7], it would be recommended that reference ranges or cutoffs of SAD should be lower in women than in men when using SAD to assess the obesity-related health risk in clinical application and practice. SAD increased with age and increased more rapidly before age of 50 years than after age of 50 years in both women and men, implying that on the average, more amount of visceral fat gain was detected in younger age ( $<50$ years) than older age ( $\geq 50$ years). The findings inform the development of education, exercise, and/or diet based programs that target younger populations for control of rapid visceral fat accumulation and for prevention of health risk in the later life. The racial/ethnic difference in SAD (typically, Asian and Hispanic <nonHispanic white $<$ non-Hispanic black) provide some evidence for adopting different cut points across racial groups for defining the SAD-related obesity, yet further study with focus on racial/ethnic minority groups needs to be investigated. Analysis of SAD correlates indicates that women and men may share the same group of socioeconomic factors in relation to SAD.

\section{Supplementary Information}

Supplementary information accompanies this paper at https://doi.org/10. 1186/s12889-020-09805-Z.

Additional file 1: Supplemental table 1. Correlations between $B M I$, WC, and SAD.

\section{Abbreviations}

BMI: Body mass index; Cl: Confidence interval; NHANES: National Health and Nutrition Examination Survey; SAD: Sagittal abdominal diameter; WC: Waist circumference

\section{Acknowledgements}

Dr. Yakusheva provided insightful comments on the revised manuscript. We are grateful to her for the comments to improve the quality of the manuscript. We thank the National Center for Health Statistics for the availability of NHANES data.

\section{Authors' contributions}

$\mathrm{CL}$ analyzed the data, participated in the manuscript writing and revision, finalized the results, and made the tables and figures. MH and SZL provided critical comments on the design and the results and conceived the study ideas. DT provided comments on data sources and the manuscript and generated feedback for the revised manuscript. YS involved data collection, management, and result interpretation. XFL wrote and revised the manuscript and charged the overall direction and planning. All authors participated in the discussion and contributed to the final manuscript. All authors read and approved the submission of the final manuscript to BMC Public Health.

\section{Funding}

The projected is funded by MCubed sponsored by the University of Michigan. The funding has been used to support collection, analysis, and interpretation of data.

\section{Availability of data and materials}

Final analysis data will be available to the researchers upon request via email at liuxf@umich.edu or by mail to Dr. Xuefeng Liu, Department of Department of Systems, Populations and Leadership, University of Michigan, 400 North Ingalls Building, Ann Arbor, Ml 48109. The general data can be found by clicking on the link https://wwwn.cdc.gov/nchs/nhanes/Default.aspx.

\section{Ethics approval and consent to participate}

All the participants gave informed written consent, and the survey was approved by the National Center for Health Statistics Institutional/Ethics Review Board.

\section{Consent for publication}

Not applicable.

Competing interests

The authors declare no conflicts of interest in the present study.

\section{Author details}

${ }^{1}$ Department of Systems, Population, and Leadership, University of Michigan School of Nursing, Ann Arbor, Ml 48109, USA. ${ }^{2}$ Department of Family Medicine, Wayne State University School of Medicine, Detroit, MI 48202, USA. ${ }^{3}$ Department of Internal Medicine, University of Michigan School of Medicine, Ann Arbor, Ml 48109, USA. ${ }^{4}$ School of Nursing, Indiana University, Indianapolis, IN 46202, USA. ${ }^{5}$ Frankel Cardiovascular Center, University of Michigan School of Medicine, Ann Arbor, MI 48109, USA.

Received: 16 January 2020 Accepted: 30 October 2020

Published online: 11 March 2021

\section{References}

1. Fox CS, Massaro JM, Hoffmann U, et al. Abdominal visceral and subcutaneous adipose tissue compartments - association with metabolic risk factors in the Framingham heart study. Circulation. 2007;116(1):39-48. 
2. Liu JK, Fox CS, Hickson DA, et al. Impact of abdominal visceral and subcutaneous adipose tissue on Cardiometabolic risk factors: the Jackson heart study. J Clin Endocr Metab. 2010;95(12):5419-26.

3. Yim JY, Kim D, Lim SH, et al. Sagittal abdominal diameter is a strong anthropometric measure of visceral adipose tissue in the Asian general population. Diabetes Care. 2010;33(12):2665-70.

4. Riserus U, Arnlov J, Brismar K, Zethelius B, Berglund L, Vessby B. Sagittal abdominal diameter is a strong anthropometric marker of insulin resistance and hyperproinsulinemia in obese men. Diabetes Care. 2004;27(8):2041-6.

5. Ohrvall M, Berglund L, Vessby B. Sagittal abdominal diameter compared with other anthropometric measurements in relation to cardiovascular risk. Int J Obesity. 2000;24(4):497-501.

6. Pajunen $\mathrm{P}$, Rissanen $\mathrm{H}$, Laaksonen MA, Heliovaara M, Reunanen A, Knekt P. Sagittal abdominal diameter as a new predictor for incident diabetes. Diabetes Care. 2013:36(2):283-8.

7. Iribarren C, Darbinian JA, LO JC, Fireman BH, Go AS. Value of the sagittal abdominal diameter in coronary heart disease risk assessment: cohort study in a large, multiethnic population. Am J Epidemiol. 2006;164(12):1150-9.

8. Empana JP, Ducimetiere P, Charles MA, Jouven X. Sagittal abdominal diameter and risk of sudden death in asymptomatic middle-aged men: the Paris prospective study I. Circulation. 2004;110(18):2781-5.

9. Lee MJ, Shin DH, Kim SJ, et al. Sagittal Abdominal Diameter Is an Independent Predictor of All-Cause and Cardiovascular Mortality in Incident Peritoneal Dialysis Patients. Plos One. 2013;8(10):e77082.

10. Demerath EW, Sun SS, Rogers N, et al. Anatomical patterning of visceral adipose tissue: race, sex, and age variation. Obesity (Silver Spring). 2007; 15(12):2984-93.

11. Schreiner PJ, Terry JG, Evans GW, Hinson WH, Crouse JR 3rd, Heiss G. Sexspecific associations of magnetic resonance imaging-derived intraabdominal and subcutaneous fat areas with conventional anthropometric indices. The atherosclerosis risk in communities study. Am J Epidemiol. 1996;144(4):335-45.

12. Camhi SM, Bray GA, Bouchard C, et al. The relationship of waist circumference and BMI to visceral, subcutaneous, and total body fat: sex and race differences. Obesity (Silver Spring). 2011;19(2):402-8.

13. Kahn HS, Bullard KM. Indicators of abdominal size relative to height associated with sex, age, socioeconomic position and ancestry among US adults. PLoS One. 2017;12(3):e0172245.

14. Sampaio LR, Simoes EJ, Assis $A M O$, Ramos LR. Validity and reliability of the sagittal abdominal diameter as a predictor of visceral abdominal fat. Arq Bras Endocrinol. 2007;51(6):980-6.

15. Kahn HS, Rissanen H, Bullard KM, Knekt P. The population distribution of the sagittal abdominal diameter (SAD) and SAD/height ratio among Finnish adults. Clin Obes. 2014;4(6):333-41.

16. Mosca L, Barrett-Connor E, Wenger NK. Sex/gender differences in cardiovascular disease prevention: what a difference a decade makes. Circulation. 2011;124(19):2145-54

17. National Center for Health Statistics. National Health and Nutrition Examination Survey: Plan and Operations, 1999-2010. https://www.cdc.gov/ nchs/data/series/sr_01/sr01_056.pdf. Accessed February 28, 2019.

18. National Center for Health Statistics. Introduction to national health and nutrition examination survey. https://www.cdc.gov/nchs/data/nhanes/ nhanes_13_14/NHANES_Overview_Brochure.pdf. Accessed February 28, 2019.

19. National Center for Health Statistics. Centers for Disease Control and Prevention. National Health and Nutritioin Examination Survey: Anthropometry Procedures Manual; 2016. https://wwwn.cdc.gov/nchs/data/ nhanes/2015-2016/manuals/2016_Anthropometry_Procedures_Manual.pdf. Accessed February 16, 2019.

20. National Center for Health Statistics, Centers for Disease Control and Prevention. National Health and Nutrition Examination Survey: analytic guidelines, 1999-2010. http://www.cdc.gov/nchs/data/nhanes/analytic_ guidelines_11_12.pdf. Accessed December 20, 2018.

21. Kuk JL, Lee $S$, Heymsfield SB, Ross R. Waist circumference and abdominal adipose tissue distribution: influence of age and sex. Am J Clin Nutr. 2005; 81(6):1330-4.

22. Stevens J, Katz EG, Huxley RR. Associations between gender, age and waist circumference. Eur J Clin Nutr. 2010;64(1):6-15.

23. Ford ES, Maynard LM, Li C. Trends in mean waist circumference and abdominal obesity among US adults, 1999-2012. JAMA. 2014;312(11):1151-3.
24. Wells JC, Cole TJ, Treleaven P. Age-variability in body shape associated with excess weight: the UK National Sizing Survey. Obesity (Silver Spring). 2008; 16(2):435-41.

25. Ko GT, Chan JC, Woo J, et al. Simple anthropometric indexes and cardiovascular risk factors in Chinese. Int J Obes Relat Metab Disord. 1997; 21(11):995-1001.

26. Berber A, Gomez-Santos R, Fanghanel G, Sanchez-Reyes L. Anthropometric indexes in the prediction of type 2 diabetes mellitus, hypertension and dyslipidaemia in a Mexican population. Int J Obes Relat Metab Disord. 2001 25(12):1794-9.

27. Flint AJ, Rexrode KM, Hu FB, et al. Body mass index, waist circumference, and risk of coronary heart disease: a prospective study among men and women. Obes Res Clin Pract. 2010;4(3):E171-81.

28. Peters SAE, Bots SH, Woodward M. Sex Differences in the Association Between Measures of General and Central Adiposity and the Risk of Myocardial Infarction: Results From the UK Biobank. J Am Heart Assoc. 2018; 7(5):e008507.

29. Nakata K, Choo J, Hopson MJS, et al. Stronger associations of sagittal abdominal diameter with atherogenic lipoprotein subfractions than waist circumference in middle-aged US white and Japanese men. Metab Clin Exp. 2010;59(12):1742-51.

30. Wajchenberg BL. Subcutaneous and visceral adipose tissue: their relation to the metabolic syndrome. Endocr Rev. 2000;21(6):697-738

31. Cartwright MJ, Tchkonia T, Kirkland JL. Aging in adipocytes: potential impact of inherent, depot-specific mechanisms. Exp Gerontol. 2007;42(6):463-71.

32. Klein S, Allison DB, Heymsfield SB, et al. Waist circumference and cardiometabolic risk: a consensus statement from shaping America's health: Association for Weight Management and Obesity Prevention; NAASO, the Obesity Society; the American Society for Nutrition; and the American Diabetes Association. Diabetes Care. 2007;30(6):1647-52.

33. Fryar CD, Kruszon-Moran D, Gu Q, Ogden CL. Mean Body Weight, Height, Waist Circumference, and Body Mass Index Among Adults: United States, 1999-2000 Through 2015-2016. Natl Health Stat Report. 2018:(122):1-16. PMID: 30707668

\section{Publisher's Note}

Springer Nature remains neutral with regard to jurisdictional claims in published maps and institutional affiliations.

Ready to submit your research? Choose BMC and benefit from:

- fast, convenient online submission

- thorough peer review by experienced researchers in your field

- rapid publication on acceptance

- support for research data, including large and complex data types

- gold Open Access which fosters wider collaboration and increased citations

- maximum visibility for your research: over $100 \mathrm{M}$ website views per year

At $\mathrm{BMC}$, research is always in progress.

Learn more biomedcentral.com/submissions 